\title{
STUDY ON ANTHROPOMETRIC MEASUREMENTS OF SCHOOL-AGED BOYS IN PÄRNU CITY
}

\author{
Kandela Õun ${ }^{1,2}$, Handreas Hallimä̈ ${ }^{2}$, Evert SaArnaK ${ }^{2}$, \\ SirJe Miglai ${ }^{2}$ \\ ${ }^{1}$ Research Centre of Pärnu College, University of Tartu, Pärnu, Estonia; \\ ${ }^{2}$ Pärnu Koidula Gymnasium, Pärnu, Estonia
}

\begin{abstract}
In 2018, a study on boys' anthropometry was conducted in Pärnu Koidula Gymnasium (referred to as PKG) as a school research project. 214 highschool boys, aged 17-19 years, participated in the study. The young men of PKG have thicker but shorter legs than the boys measured by Juhan Aul 1932-1940. Compared to the norms developed in 2017 by Kaarma et al. [6], the 17-year-old boys of PKG are on average $3 \mathrm{~cm}$ taller and $5.1 \mathrm{~kg}$ heavier, the 18-year-old boys do not differ so much from the standards. The 17-yearolds' trunk index mean value has a statistically significantly lower value compared to the 18 -year-olds (mean difference $-0.897, \mathrm{p}=0.031$ ). The somatotypes classification analysis showed that the number of 17-year-old boys in the LARGE class is three times higher compared to the 2017 norms. The number of 18-year-olds in pycnomorfs 3 (P3) class is twice as much as the number of boys reported in the norms. Some anthropometrical indexes are more related to the SD classifications than others are. Compared to earlier measurements, the current results reported similar acceleration as other researchers had.
\end{abstract}

Keywords: somatotypes; SD-classes; anthropometric indices; schoolboys' measurements

\section{INTRODUCTION}

Anthropological research on is important because it enables us to look at the evolutionary development of a person over the years and provides valuable comparative information for future generations for similar studies conducted 
in the future. At the same time, anthropology gives the opportunity to explore how a person changes with age.

Physical anthropology is research of human biological evolution which analyses the physical dimensions and peculiarities of a population. In addition, the natural anthropology-related discipline also studies race formation and susceptibility to various diseases, comparing people living in different environments. Physical anthropology studies several physical dimensions of the human body, but the most typical measurements are body height and weight. [1]

According to Maiste et al. [8], body height is considered to be the primary anthropometric feature that is closely correlated with other body characteristics. Body height is the basis for evaluating all other body dimensions, proportions, and body types. In addition, the change in population's average of body height reflects the population's health and nutritional status, especially during the growth period in 7-18 years of age. [8]

In addition to overall height, the most important measurements for the evaluation of health and ability to work are the lengths of legs, arms, head, neck and their relationship to height [8]. Another important measure is body weight which characterizes the massiveness of the person and the level of corpulence [1].

Children's age and weight are assessed using national age and gender standards, which are recommended to be updated every 10-15 years. Grünberg et al. [4] developed a growth-weight curve of different genders and nationalities based on data gathered in 1996. Their growth-weight curve has a percent distribution of body weight for a given height, which allows to assess the child's development year by year.

The basic type of physical development of the human body is mostly genetically determined, but it is important to evaluate the body proportions, which, in the case of adolescents, can influence the choice of sport and exercise. For example, persons whose body is taller than the average are not as skilful on the track as persons with shorter body height. At the same time, pupils with a weak body are not able to achieve results comparable with strong and big pupils. [8]

Various indices have been developed to help better analyse the nature of the human body and its needs; some of the most popular ones are also used in this article. The ratio of body weight to height expresses body proportions. The following formula used to find the body mass index (BMI) as one of the most common and easy-to-use body growth ratios [1]: 


$$
B M I=\frac{\text { body weight }(\mathrm{kg})}{\text { body height }{ }^{2}\left(\mathrm{~m}^{2}\right)} .
$$

The index determines obesity and assesses the risk of developing cardiovascular disease. For adults, a body mass index of less than 19 is considered as underweight, from 19 to 24.9 as normal weight and 25-29.9 as overweight. If the body mass index is 30 or more, the person is obese [12]. For detecting overweight and obesity in children and youths aged 2-18 years, BMI norms based on a wide international study have been presented [3]. Those norms have gained wide popularity but also raised a dispute on the use of global vs local cut-off points [2,9], as those points have been reported to be rather population-specific. [11]

One of the most important indicators of body proportions is the trunk index or percentage of the trunk in body height. The trunk index is calculated using the following formula:

$$
\text { Trunk index }=\frac{\text { sitting height }(\mathrm{cm}) \times 100}{\text { body height }(\mathrm{cm})} .
$$

A small trunk index indicates that the body is slender, a high trunk index, however, that the body is stocky [1].

The intermembrane index provides a good overview of the overall proportions of the body. The intermembrane index indicates the ratio of the length of the upper and lower limbs and is calculated by the following formula [1]:

$$
\text { Intermebrane index }=\frac{\text { lenght of the upper } \operatorname{limb}(\mathrm{cm}) \times 100}{\text { lenght of the lower } \operatorname{limb}(\mathrm{cm})} .
$$

Rohrer's index shows the level of development of the body with respect to length (proportion or corpulence), and it is found as follows [1]:

$$
\text { Rohrer's index }=\frac{\text { body weight }(\mathrm{g}) \times 100}{\text { body height }{ }^{3}\left(\mathrm{~cm}^{3}\right)} \text {. }
$$

For Rohrer's index, human body weight (volume) expressed as a cube. The index represents the percentage of the volume of that cube compared to the volume of the cube whose edge length is equal to the person's height. As the index grows, body corpulence also increases. The higher Rohrer's index, the higher the relative weight [5]. Body height and the corpulence index are inversely related, i.e., with a decrease in body height, the body's corpulence index increases. 
An important trend in physical anthropology is acceleration (secular trend) which means the average growth in height and other anthropometric dimensions of one generation of children compared to previous generations. This trend is particularly relevant in European countries and the US. The causes of the phenomenon are not precisely known - external influences, especially diet and exercise, are considered important. In a narrower sense, acceleration is accelerated growth and development of a child compared to their peers; the difference can be up to two years. Acceleration is not comparable to early sexual maturation where the difference between biological and chronological age exceeds two years [8].

The first data on anthropological measurements of schoolchildren of Estonian origin date back to the end of the 19th century. In 1888, Ch. Ströhmberg who was a school doctor in Tartu Alexander Upper Secondary School published the body height and chest circumference data of 465 students aged 10-21 years. Since Germans, Estonians, Russians and students of other ethnicities were studying in the upper secondary school at that time, Ströhmberg's material was mixed in terms of ethnicity. As the data were given by name, Estonians could be found among the measured students with minor errors. Since Ströhmberg's data were the only ones at that time, they were considered quite important [1].

H. Madisson, also a school doctor, collected the next height and weight measurements of schoolchildren in Tartu in 1922. The data were collected from 805 boys and 562 girls aged 7-17, and as these measurements were affected by the aftermath of the heavy war years, the database remains very important to this day. Next, in 1932-1940, Juhan Aul collected anthropological data in different schools all over Estonia based on a broader programme. As the time was limited, material collection was sporadic, and, therefore, its quality might be questionable; however, the survey results still provide a good overview of the physical development of the schoolchildren at that time, and they are considered as reference data [1]. During Aul's research, certain methods of measuring different dimensions and lengths of human body were developed. 

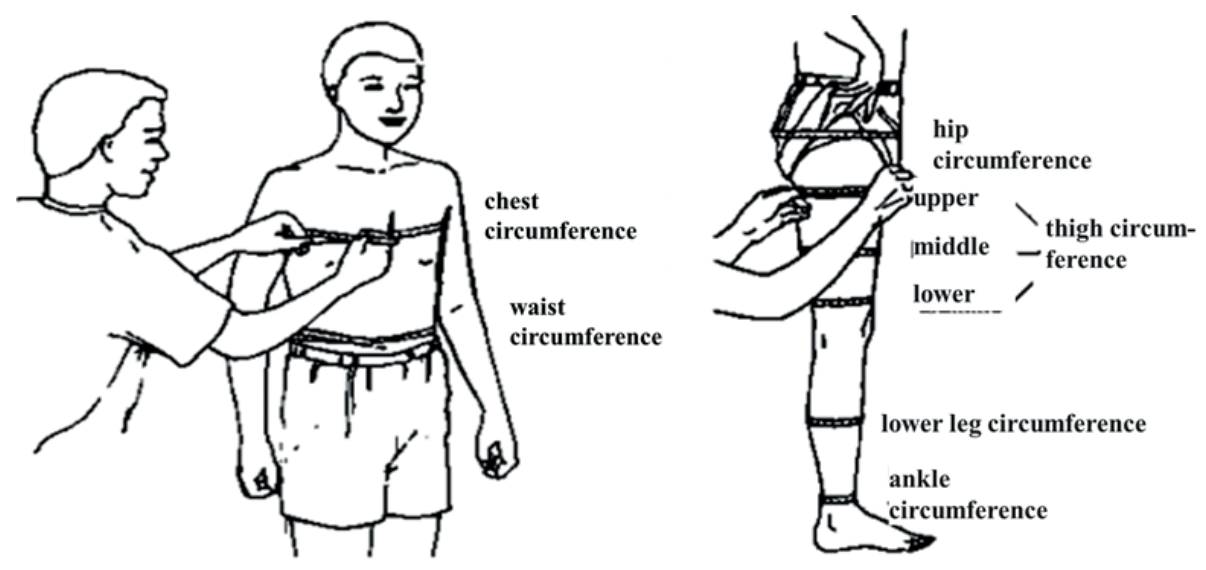

Figure 1. Instructions for measuring different circumferences (Docherty, 1996, referenced by [8])

In 1956, the results of E. Närska's extensive measurements of schoolchildren's physical development in Tallinn were published. The material included 1225 male and 1266 female students aged from 8 to 17 years. These data were used to compare and evaluate the results ten years later when a similar survey was conducted in Tallinn. In 1956, J. Aul started the creation of an anthropological database of 7-18-year-old schoolchildren. This work lasted until 1967. In 1960 , based on the materials collected by that time, J. Aul published a preliminary partial review on the physical development of school pupils in relation to the treatment of the age when weight is at its relative low point and maturity ratio [1].

In 1964, Aul spoke about the physical development of school students at the VII International Congress of Anthropologists and Ethnographers. In 1970, when the collection of material, which was started in 1956, was completed and the data were properly analysed, Aul gave a brief overview of the physical development of the Estonian youth and the corresponding regularities on the basis of this material at the 2nd International Congress for Finno-Ugric Studies (CIFU) [1].

Several researchers, in cooperation with the Centre for Physical Anthropology at the University of Tartu, have continued the work of Juhan Aul in Estonia. The Centre has achieved success in studying the regularities of body build structure. Researchers have developed the weight and height norms for infants, children and school students and the rules of somatotyping [4, 7, 8, 10]. The first growth charts were compiled and used in Estonia in 1993. These charts were based on cross-sectional and longitudinal measurements 
of children's height and weight conducted in the 1970s. The next norms were developed based on the data collected in 1996 and were still used in schools in 2013 [10].

Researchers have also analysed the acceleration of children's measurements. A comparison of 2006-2009 measurements with the results of 1996 by means by statistical tests [10] confirmed that "during the interim period, the development of Estonian schoolchildren has changed. Children are significantly taller (boys by $4.84 \mathrm{~cm}$ and girls by $3.86 \mathrm{~cm}$ on average) and heavier (boys by $5.90 \mathrm{~kg}$ and girls by $4.20 \mathrm{~kg}$ on average). The mean body mass index has also increased significantly (in boys by 1.30 units and in girls by 0.99 units on average)" [10]. Compared to the growth rate graphs of 1996, the peaks have moved to approximately a year earlier in both sexes [10].

\section{MATERIAL AND METHODS}

The students of Pärnu Koidula Gymnasium (H. Hallimäe and E. Saarnak) measured the anthropological indicators of schoolboys in PKG to complete their 11th grade research project. The authors acquired the knowledge necessary for measuring from Juhan Aul's Anthropology of Estonian School Students and from the school nurse who initially helped the authors to measure the subjects. The measuring instruments used (scales and measuring tape) were in the school nurse's room. The targeted sample included 214 boys from PKG. The measurements were taken from 5 March to 9 April 2018, and the parameters were measured in millimetres using a measuring tape. The students were invited to take the measurements at the school nurse's office in 2-3 person groups and the average measurement of a student lasted approximately 4 minutes.

The body height was measured using a measuring device available in the school doctor's office. The boys were asked to remove their shoes, to stand upright by the wall, and place their heels against the wall. For the measuring of body weight, the subjects were asked to remove footwear, outerwear and weight-adding items from their pockets. For measuring the sitting height (the range from the head to the tailbone), the students were asked to sit on the seat and keep the back straight.

To measure the shoulder width, the subjects were asked to keep the upper body straight and the shoulders free. The chest circumference was obtained by measuring from behind the back of the students, asking them to raise their hands at the time when the tape was placed around the body and then lowered 
again to obtain an accurate result when the chest was in its natural state. The width of the chest is the distance between the shoulder blades in millimetres, and to measure it, the subjects were asked to bend over slightly so that the shoulder blades could be felt. The hip circumference was measured over the buttocks and for this, the measured ones were asked to stand up to the meter with their back. The length of the upper limb is the distance between the shoulder and the middle finger in millimetres. To measure this, students were asked to stretch their hands and fingers to their side. The length of the lower limb is measured from the upper end of the femur to the foot in millimetres. To measure the length of the leg, the pupils had to stand firmly on two legs and hold their feet straight and face the side of the measurer. In order to obtain the exact result of the circumference of the thigh, the pupils were asked to stand upright so that the thigh would be in a resting position and there would be no tension. To measure the circumference of the head, the authors placed the tape around the widest area of the head.

To describe the physique, body somatotypes were developed by dividing both length and weight by mean and standard deviation into three classes and placing them in a cross-table to obtain the distribution of 9 classic body types. That unified classification for characterization of body build consists of the following five classes: small, medium, large, pycnomorphs, leptomorphs. The classes of pycnomorphs and leptomorphs were respectively divided into three subclasses $[6,7]$.

The ANOVA test was carried out to analyse statistically significant differences of measurements in height, weight and somatotypes classes.

\section{RESULTS}

The average body height of the young men of PKG was $10.9 \mathrm{~cm}$ taller and the body weight $13.7 \mathrm{~kg}$ heavier than in Aul's results. The average thigh circumference of the young men of PKG was $3.7 \mathrm{~cm}$ bigger, but the average length of the lower limb was $0.9 \mathrm{~cm}$ shorter than in Aul's results. It can be concluded that the young men of PKG have thicker but shorter legs than the boys measured by Juhan Aul.

In 2017, new norms for youngsters aged 7-18 years were presented by Kaarma et al. [6] and, compared to them (see Table 1), the 17-year-old boys of PKG were $3 \mathrm{~cm}$ taller and $5.1 \mathrm{~kg}$ heavier. 18-year-old boys did not differ greatly from the standards, however, being on average $0.6 \mathrm{~cm}$ taller and $2.3 \mathrm{~kg}$ heavier. 
Table 1. Comparison of PKG boys' body height and weight values to the norms developed in 2017 and Aul's data from 1932-1940.

\begin{tabular}{|c|c|c|c|c|c|c|c|}
\hline \multirow{2}{*}{\multicolumn{2}{|c|}{ Age }} & \multicolumn{2}{|c|}{ PKG } & \multicolumn{2}{|c|}{2017 norms } & \multicolumn{2}{|c|}{$1932-1940$ results } \\
\hline & & Height & Weight & Height & Weight & Height & Weight \\
\hline \multirow{4}{*}{17} & Minimum & 164.5 & 44.1 & 162.0 & 47.0 & & \\
\hline & Maximum & 202.5 & 116.5 & 202.0 & 107.0 & & \\
\hline & Mean & 183.8 & 76.4 & 180.8 & 71.5 & 169.74 & 61 \\
\hline & SD & 7.4 & 13.8 & 6.2 & 11.1 & 7.32 & 8.5 \\
\hline \multirow{4}{*}{18} & Minimum & 155.0 & 47.4 & 160.0 & 47.0 & & \\
\hline & Maximum & 198.5 & 123.0 & 200.1 & 110.0 & & \\
\hline & Mean & 181.9 & 76.8 & 181.3 & 74.5 & 171.65 & 65.76 \\
\hline & SD & 7.1 & 14.5 & 6.5 & 11.1 & 6.28 & 6.9 \\
\hline \multirow{4}{*}{19} & Minimum & 165.3 & 57.8 & & & & \\
\hline & Maximum & 195.1 & 118.1 & & & & \\
\hline & Mean & 183.1 & 77.9 & & & 172.40 & 67.24 \\
\hline & SD & 6.2 & 10.7 & & & 5.72 & 6.9 \\
\hline
\end{tabular}

Comparing 17-, 18-, and 19-year-old young men of PKG, we can say that statistically significant differences are present in three variables. 17-year-olds' trunk index mean value has a statistically significantly lower value compared to the 18 -year-olds (mean difference $-0.897, \mathrm{p}=0.031$ ) and the mean values of 17-year-olds' shoulder width and chest circumference are statistically significantly lower than same values of 19-year-olds (mean difference of shoulder width $-1,564, p=0,002$; mean difference of chest circumference $-3,283$, $\mathrm{p}=0,036$ ).

To compare PKG boys by height and weight SD-classes (see Table 2), the mean and standard deviation of height and weight were calculated in three age groups $(17,18,19$ years) and three SD-classes of height and weight were created based on the body type methodology of Kaarma et al [7]. 
Table 2. Height, weight and somatotypes SD-classes' counts and distributions by age $(n=214)$. > Number of subjects and their distribution by age in height, weight and somatotypes SD-classes.

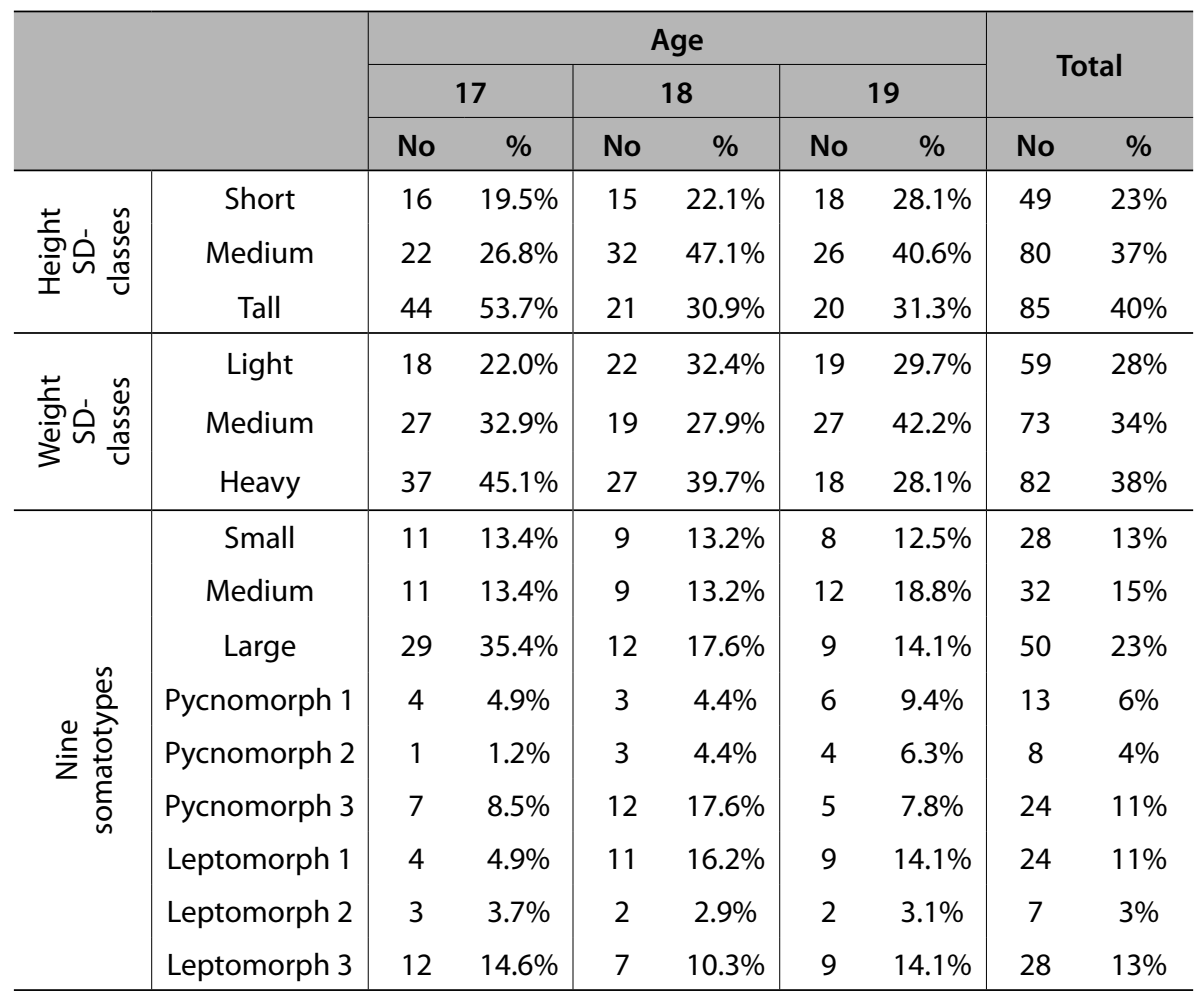

To compare PKG boys' somatotypes to the norms developed by Kaarma et al in 2017, the mean and standard deviation of height and weight in three age groups $(17,18,19$ years) was calculated and distributed into nine somatotypes (see Figure 2).

The distribution of nine somatotypes shows the differences of PKG boys from norms. First, the biggest difference is the three times larger number of 17 -year-old boys in the LARGE class and almost half of the number of pycnomorphs 1 (P1) and leptomorphs 1 (L1) compared the 2017 norms. To compare the 18-year-olds, there are twice as many boys in the pycnomorphs 3 (P3) class as the norms reported. 


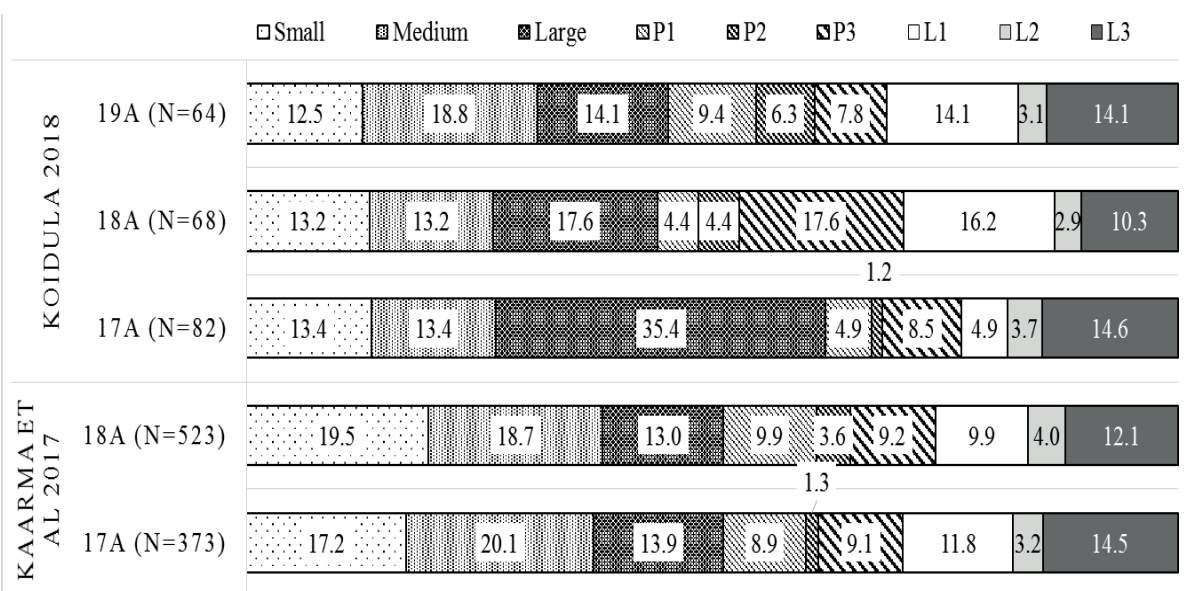

Figure 2. The distribution (\% of the $\mathrm{N}$ value) of somatotypes in 17-19-year-old PKG boys and norms developed 2017. ( $\mathrm{P}$ - pycnomorph, $\mathrm{L}$ - leptomorph)

Statistically significant differences appeared (see Table 4 and average values in Table 3) between all weight classes (LIGHT, MEDIUM, HEAVY) in the average values of Rohrer's index, thigh circumference, hip circumference and upper and lower limb length. In the three height classes (SHORT, MEDIUM, TALL) statistically different average values were registered in lower and upper limb length, sitting height, body height and body weight. In the SHORT and TALL classes, statistically different mean values were noticed in the trunk index, shoulder width, hip circumference, head circumference and Rohrer's index, and in the SHORT and MEDIUM classes, in the shoulder and hip circumference.

The comparison of the measured variables by the nine somatotypes revealed that only two variables (the intermembral index and mean head length) did not show statistically significant differences $(p>=0.05)$. The trunk index had slightly significant differences with the Bonferroni Post Hoc Test between Leptomorph 1 and Pycnomorph $1(\mathrm{p}=0.049)$ and Leptomorph 1 and Pycnomorph $2(\mathrm{p}=0.037$ 


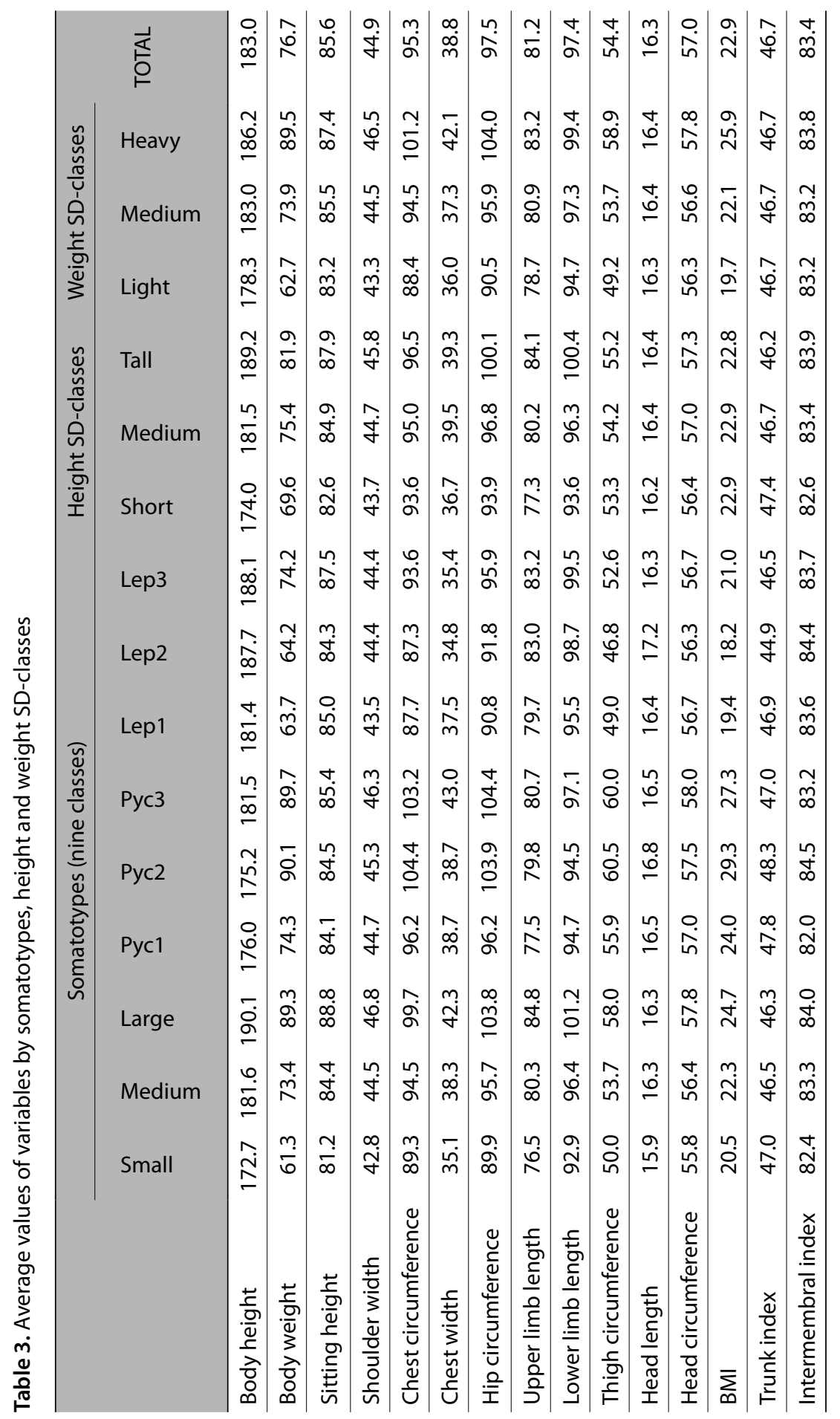


Table 4. ANOVA test F-statistics and $p$-values

\begin{tabular}{|c|c|c|c|c|c|c|}
\hline \multirow{2}{*}{ Variables } & \multicolumn{2}{|c|}{ Weight SD-classes } & \multicolumn{2}{|c|}{ Height SD-classes } & \multicolumn{2}{|c|}{ Nine somatotypes } \\
\hline & F-stat & p-value & F-stat & p-value & F-stat & p-value \\
\hline Body height & 28.445 & $0.000^{* * * *}$ & 285.218 & $0.000^{* * * *}$ & 76.579 & $0.000^{* * *}$ \\
\hline Body weight & 253.791 & $0.000^{* * * *}$ & 17.349 & $0.000^{* * * *}$ & 62.645 & $0.000^{* * *}$ \\
\hline BMI & 120.373 & $0.000^{* * *}$ & 0.014 & 0.986 & 50.300 & $0.000^{* * *}$ \\
\hline Sitting height & 22.795 & $0.000^{* * *}$ & 40.984 & $0.000^{* * *}$ & 14.438 & $0.000^{* * *}$ \\
\hline Trunk index & 0.022 & 0.978 & 5.242 & $0.006^{* *}$ & 2.354 & $0.019^{*}$ \\
\hline Shoulder width & 31.643 & $0.000^{* * *}$ & 9.999 & $0.000^{* * *}$ & 8.680 & $0.000^{* * *}$ \\
\hline Chest circumference & 85.521 & $0.000^{* * *}$ & 2.282 & 0.105 & 23.433 & $0.000 * * *$ \\
\hline Chest width & 11.985 & $0.000^{* * *}$ & 1.966 & 0.143 & 3.679 & $0.000^{* * *}$ \\
\hline Hip circumference & 152.298 & $0.000^{* * *}$ & 13.724 & $0.000^{* * * *}$ & 37.488 & $0.000^{* * *}$ \\
\hline Upper limb length & 29.301 & $0.000^{* * *}$ & 100.868 & $0.000^{* * * *}$ & 29.021 & $0.000^{* * *}$ \\
\hline Lower limb length & 20.623 & $0.000^{* * *}$ & 54.304 & $0.000^{* * *}$ & 15.206 & $0.000^{* * *}$ \\
\hline Intermembral index & 0.699 & 0.498 & 2.083 & 0.127 & 0.875 & 0.538 \\
\hline Thigh circumference & 138.504 & $0.000^{* * *}$ & 2.088 & 0.126 & 40.213 & $0.000^{* * *}$ \\
\hline Head length & 0.065 & 0.938 & 0.369 & 0.692 & 0.877 & 0.537 \\
\hline Head circumference & 27.568 & $0.000^{* * *}$ & 5.078 & $0.007^{* *}$ & 8.001 & $0.000^{* * *}$ \\
\hline Rohrer's index & 62.378 & $0.000^{* * * *}$ & 5.248 & $0.006^{* *}$ & 47.809 & $0.000^{* * *}$ \\
\hline
\end{tabular}

${ }^{* * *} p<0.001,{ }^{* *} p<0.01,{ }^{*} p<0.05$

To compare the four anthropometrical indices introduced in the theoretical part of this article, the values of indices in different SD-classes are presented in Figure 3.

The BMI and Rohrer's index have a similar pattern (both equations include weight and height quotients), and this can also be registered for the trunk and intermembral indices (both include height components). However, when changes in the trunk and intermembral indices are both close to zero compared to the total value in different SD-classes, there are bigger differences in BMI and Rohrer's index values. The explanation can be that length measurements are so-called bone measurements, and these measurements do not change as much as soft tissues, which are an important part of body weight, which is more variable than height measurements. For the same reason, there are no big differences between the BMI and Rohrer's index values in SD classes - the Rohrer's index is $5 \%$ higher in the SHORT and 3\% in the TALL SD-class. The difference in weight in the SD-classes is greater - in the LIGHT SD-class, the 
values of the Rohrer's index are more than $10 \%$ smaller and in the HEAVY class $13 \%$ higher than the overall value. Similar relationships also occur in the SD-classes of the nine somatotypes' SD-classes. Pycnomorphs who are with higher weight and smaller length are both up to $35 \%$ higher than the BMI and Rohrer index average, and leptosomes with a larger height and smaller weight value are $22 \%$ lower in the value than the mean score. So, there are differences between somatotypes, and it is important to look at the correlations and other links between anthropometric measurements and SD-classes.

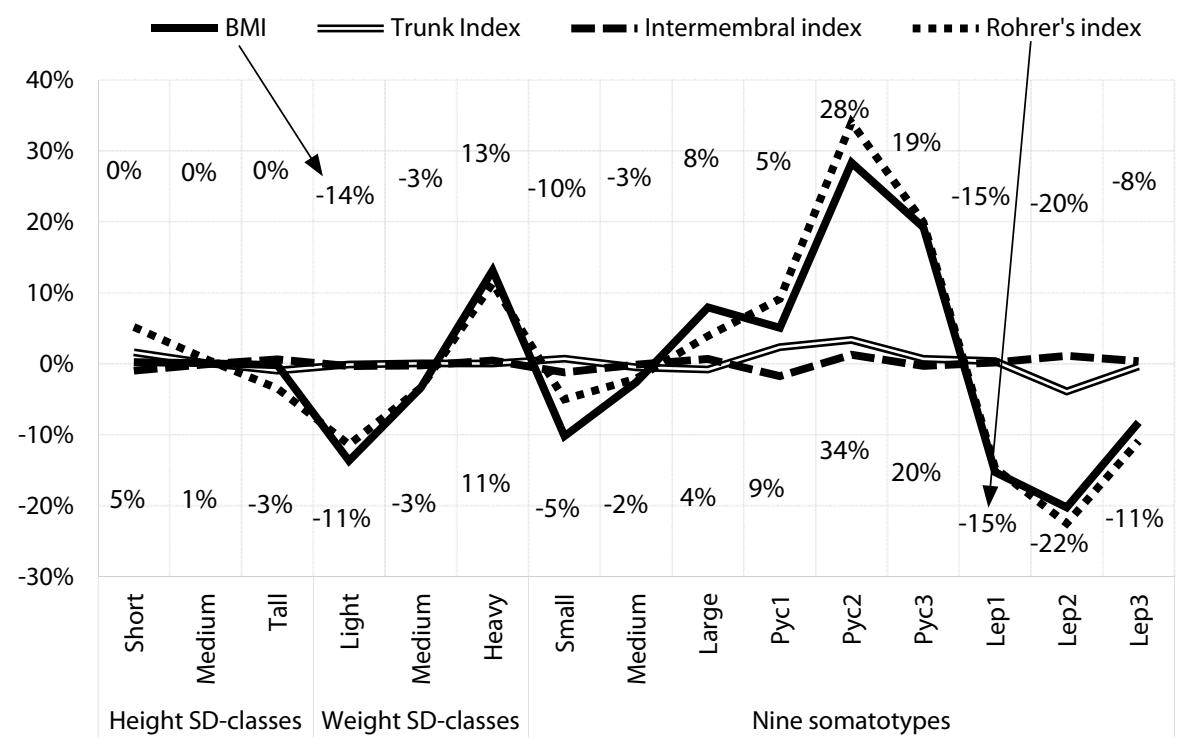

Figure 3. Values of the indices by SD-classes (percentage of the named SD-class value compared to the total value of 214 boys).

\section{DISCUSSION}

Estonian children's mean height and weight have increased. Thus, children have started to grow more quickly and reach their final height earlier, and they have become considerably heavier. Salm et al [10] have noted that "as a comparison, it can be said that between the studies conducted in 1956 and 1996, the changes in mean body mass were $0.5-2 \mathrm{~kg}$. Consequently, the schoolchildren have become stronger and more corpulent in their body build." The results of the research project in Pärnu Koidula Gymnasium have led to the conclusion that children's physical development is quicker nowadays. The hypothesis claimed that PKG boys' physical measurements are bigger than in Juhan Aul's published records. The experiment proved the hypothesis to be right. 
Compared to Juhan Aul's records, Pärnu Koidula Gymnasium's boys' average height was $10.9 \mathrm{~cm}$ higher and body mass $13.7 \mathrm{~kg}$ heavier, which shows that Koidula's boys are physically larger. The average thigh circumference in schoolboys was bigger by $3.7 \mathrm{~cm}$, but the average leg length was $0.9 \mathrm{~cm}$ shorter than in the boys measured by J. Aul. From these results, it can be concluded that Koidula Gymnasium's young men have thicker thighs but shorter legs. One can also conclude that there is acceleration in boys' measurements, and there are interesting links between body type and anthropometrical measurements.

To conclude, the school research project was interesting for the young authors and they got valuable experience in the field of anthropometry. They would also like to thank their supervisor, teacher of biology Sirje Miglai, and teacher of research methodology Kandela Õun who helped to write this article.

\section{REFERENCES}

1. Aul J. (1982). Eesti kooliõpilaste antropoloogia. Tallinn: Valgus.

2. Chinn S., Rona R.J. (2002). International definitions of overweight and obesity for children: a lasting solution? Annals of Human Biology, 29, 3, 306-313. https://doi.org/10.1080/03014460110085340

3. Cole T.J., Bellizzi M.C., Flegal K.M., Dietz W.H. (2000). Establishing a standard definition for child overweight and obesity worldwide: international survey. British Medical Journal, 320, 7244, 1-6.

https://doi.org/10.1136/bmj.320.7244.1240

4. Grünberg H., Adojaan B., Thetloff M. (1998). Kasvamine ja kasvuhäired: metoodiline juhend laste füüsilise arengu hindamiseks. Tartu: Tartu Ülikool.

5. Heapost L. (1984). Tallinna kooliõpilaste ealine antropoloogia 1966-1969. Tallinn: Valgus.

6. Kaarma H., Veldre G., Saluste L., Lintsi M., Kasmel J., Tiit E.-M., Toomsalu M., Arend A. (2017). On systematisation of Estonians' body build data. Papers on Anthropology, 26, 1, 9-27. https://doi.org/10.12697/poa.2017.26.1.01

7. Kaarma H., Veldre G., Saluste L., Lintsi M., Kasmel J., Tiit E.-M., Stamm R., Toomsalu M., Salm E., Käärik E., Arend A. (2018). Height-weight classification of Estonian schoolchildren aged 7-18 years. Papers on Anthropology, 27, 1, 17-24. https://doi.org/10.12697/poa.2018.27.1.02

8. Maiste E., Matsin T., Utso V. (1999). Tervise ja kehalise töövõime arendamine noorukieas. Tervise ja kehalise töövõime arendamine noorukieas. Tartu: Tartu Ülikooli Kirjastus.

9. Reilly J.J. (2002). Assessment of Childhood Obesity: National Reference Data or International Approach? Obesity Research, 10, 8, 838-840.

https://doi.org/10.1038/oby.2002.113 
10. Salm E., Kärik E., Kaarma H. (2013). The growth charts of Estonian schoolchildren. Comparative analysis. Papers on Anthropology, 22, 171-183. https://doi.org/10.12697/poa.2013.22.19

11. Stupnicki R., Tomaszewski P., Milde, K. (2013). Body mass index - proposed norms for children and youths. Papers on Anthropology, 22, 203-213. https://doi.org/10.12697/poa.2013.22.22

12. Oun K., Übner M. (2018). The link of diet and exercise habits of the inhabitants of Pärnu city with body mass index. Papers on Anthropology, 27, 1, 36-46. https://doi.org/10.12697/poa.2018.27.1.04

\author{
Address for correspondence: \\ Kandela Õun \\ Pärnu College, University of Tartu \\ Ringi 35, 80011 Pärnu, Estonia \\ E-mail: kandela.oun@ut.ee
}

